\title{
REEDUCAÇÃO E RECUPERAÇÃO ESPONTANEA DA MOTRICIDADE APÓS LESÕES DO SISTEMA NERVOSO CENTRAL
}

\author{
Abrão ANGHinaH*
}

Em revisão anterior, abordamos os aspectos relativos à recuperação espontânea da função nas lesões do sistema nervoso central (Anghinah) ${ }^{1}$. A presente revisão propõe-se a atualizar os conceitos emitidos a propósito das várias técnicas (programas de exercícios) que visam a recuperar deficits motores devidos a lesão do sistema nervoso central (SNC), propiciando assim elementos que se constituirão em pontos de partida para debater e esclarecer os intrincados mecanismos envolvidos na reeducação e recuperação espontânea da função.

Segundo Krusen (1946) ${ }^{19}$, embora no século XVI Geronimo Mercurialis tenha descrito pela primeira vez a "arte da ginástica para a cura das doenças" e Ambroise Paré haja tentado correlacionar mecanoterapia e anátomo-fisiologia, foi somente a partir do século XIX, quando Peter Ling empregou massagens e exercicios para corrigir defeitos físicos e Lapicque demonstrou experimentalmente as relações entre estímulo e resposta muscular, que as técnicas que visam a favorecer a recuperação motora foram sendo modificadas.

Jackson (1874) ${ }^{17}$ considerava fator importante na determinação do grau de recuperação sob influência da reeducação a quantidade de tecido nervoso residual íntegro e funcionante; em sua teoria de compensação Jackson admitia que, após a destruição de parte de um centro nervoso, o tecido residual e íntegro poderia compensar o destruído sob influência do reaprendizado. Mesmo em casos de hemiplegia de longa duração Franz, Scheetz e Wilson (cit. por Lashley - 1915/1916 ${ }^{20}$ ) observaram que exercícios sistemáticos promoviam certo grau de melhora no controle motor. Franz e Oden (cit. por Lashley - $1917^{20}$ ) verificaram que macacos com afecções cerebrais e com ausência de motricidade vcluntária nos quatro membros, ao serem submetidos à estimulação elétrica da área correspondente no córtex motor, recuperavam os movimentos em tempo menor do que os macacos em que o retorno da função se fazia espontaneamente Segundo a mesma linha de raciocínio, Kluver (cit. por Lashley ${ }^{20}$ ) ensinou macacos a puxarem cordéis ,aos pares) amarrados a caixas vinculadas aos estímulos a serem testados, tais como discriminação de pesos e distinção de sons, formas visuais e cores. Após destruir seletivamente e em macacos diferentes as áreas frontal, parietal e occipital do córtex cerebral verificou que: $a$ )

Clínica Neurológica (Prof. Horácio Martins Canelas) do Departamento de Neuropsiquiatria da Faculdade de Medicina da Universidade de São Paulo: * Docente-Livre. 
no pós-operatório imediato e durante as primeiras semanas os macacos puxavam os cordéis ao acaso, como se estivessem com amnésia; $b$ ) a partir de momento em que eram submetidos a programas de reeducação que visavam à comparação de pesos mediante resistência oferecida pelos cordéis, voltavam a discriminar correlatamente; $c$ ) de imediato e espontaneamente, sem que tivessem sido submetidos a aprendizado, conseguiam também distinguir os estímulos luminosos e sonoros, estímulos estes que conheciam previamente e que, aparentemente, haviam esquecido. Tais fatos vieram demonstrar que, em animais de experimentação, a reeducação facilita o retorno de associações aparentemente esquecidas. Acreditavam estes autores na possibilidade de a "amnésia aparente" decorrer da dependência funcional de um sistema que mantém relações com outros de organização mais fundamental. Os conceitos de dependência funcional e da existência de um sistema cuja organização é mais fundamental e/ou de substituição funcional de um centro lesado pela vicariância de um centro com funções semelhantes do hemisfério contralateral, permitiram explicar em parte o retorno espontâneo da função. Além disso, estudos experimentais de Marina (transplante de músculo reto externo para os locais de inserção do músculo reto interno e vice-versa, com conservação dos respectivos movimentos) e de Fuchs e Goldstein (cit. por Lashley) ${ }^{20}$, que conseguiram desenvolver uma "pseudo fovea", a ponto de produzir um campo visual com acuidade máxima no centro e uma acuidade significativamente diminuída na fovea anatômica, demonstraram a possibilidade de "reorganizaçz̃o adaptativa espontânea" sem necessidade de reeducação.

Goldstein (cit. por Lashley - $1931^{20}$ ) contesta a existência de uma função vicariante, admitindo que "a recuperação espontânea da função só ocorre quando há restauraçāo do substrato anatômico ou, mais raramente, mediante a reeducação prolongada desde que ocorra a persistência de parte do substrato anatômico com função idêntica à original".

Lashley (1933) ${ }^{20}$ submeteu os membros de um hemicorpo de macaco a treinamento intensivo, enquanto os membros do dimídio contralateral eram imobilizados durante o período em que durava a experiência. A seguir lesava o hemisfério cerebral contralateral, promovendo a paralisia dos membros submetidos ao treinamento. No pós-operatório imediato observou a transferência dos tipos de movimentos aprendidos para os membros que haviam sido imobilizados durante o período de experimentação. Diante desses fatos Lashley passou a admitir que a recuperação da função se devia à existência de vários circuitos com funções semelhantes difundidos pelo encéfalo e responsáveis pela equipotencialidade das áreas de associação do córtex cerebral.

Tais estudos experimentais sugeriam que o retorno da função mediante treinamento dependeria, em cada caso, da preservação de uma parte restrita de um sistema definido que estaria normalmente vinculado às mesmas funções.

Denny Brown (1950) ${ }^{10}$ reviu os princípios gerais propostos para explicar os mecanismos relacionados à função motora cerebral e verificou que os estudos experimentais realizados em macacos esbarram em obstáculos tais como a impossibilidade de solicitar ao animal que execute determinados movimentos em uma dada articulação, além de a recuperação da motricidade nas lesões cer 
brais de macacos ser notável e rápida. Suas observações a propósito do reflexo de preensão e dos fenômenos a ele relacionados permitiram alguns esclarecimentos. Admitia-se que a recuperação da motricidade após ablação de uma área do córtex motor estaria na dependência de mecanismos que, embora presentes e sem se manifestar, sempre acompanhavam os componentes do ato motor normal. Não havia razão para se acreditar que a ativação de uma "área nova" iria, com o decorrer do tempo, compensar ou substituir a área destruída. Ulteriormente demonstrou que a recuperação da motricidade é mais frequente em lesões do córtex motor do que nas secções do trato piramidal. Tais fatos permitiram supor que fibras oriundas de centros extrapiramidais corticais e subcorticais têm papel importante na execução de movimentos voluntários. Por outro lado, tanto o córtex sensitivo como o cerebelo contribuem para que a função motora seja normal e a lesão de um ou de ambos altera ou pode mesmo impedir a realização de movimentos voluntários.

Estudos de Helms e Page May, Bucy e Fulton, em macacos, e de Bates, no homem (cit. por Bucy $-1957^{8}$ ), demonstraram a existência de inervação ipsolateral, direta, da musculatura estriada que seria a responsável pela recuperação dos movimentos do membro inferior nas hemiplegias após lesão capsular. Observaram ainda que os movimentos voluntários recobrados graças à integridade da via direta eram de menor amplitude e menos ágeis, permitindo supor que a recuperação dos mesmos não seria exclusividade da inervação direta; por outro lado, consideravam muito difícil identificar o deficit motor em animais subprimatas submetidos à descorticação uni ou bilateral, pois, no pós-operatório imediato, a mobilização de sistemas subcorticais compensa em grande parte este déficit. Verificaram ainda estes autores que as funções menos diferenciadas do córtex podem ser compensadas espontaneamente, enquanto as mais diferenciadas, que dependem do aprendizado de novos padrões motores, permanecem deficitárias.

$\mathrm{Na}$ década de 40 foram utilizadas as primeiras técnicas (reprendizado mediante a utilização de programas de exercícios) que visavam a recobrar a motricidade de pacientes com déficits motores resultantes de lesōes do sistema nervoso. Estes métodos foram aos poucos sendo modificados e substituídos pelas hipotéticas e ainda não bem conhecidas bases neurofisiológicas sobre as quais estas idéias repousam.

Os conceitos neurofisiológicos a propósito do movimento voluntário ainda repousam em grande parte em bases teóricas sendo que, dois principios continuam a ser aceitos: 1) a evidenciação de componentes filo e ontogenéticos nos vários tipos de movimentos do recém-nato e na criança em desenvolvimento; 2) todo movimento baseia-se na integração sensitivo-motora como um todo e não em niveis superpostos, levando à dedução lógica de que qualquer tipo de alteração sensitiva afeta a integridade do movimento voluntário. Diante destas observações os investigadores passaram a admitir que, nas lesões do sistema nervoso central, a função motora se conserva dentro de padrões até certo ponto normais desde que se possa alterar os tipos de informações sensitivas a ele dirigidas. A partir de então as tentativas que visavam a modificar os estimu- 
los sensitivos passaram a se constituir no denominador comum dos métodos de terapêutica por exercícios.

O método proposto por Kabat (1952) 18 envolve várias técnicas de exercí cio com a finalidade de modificar o estímulo sensitivo em vários sentidos. Kabat afirma que este método recupera as funções mediante ativação de vias neuromusculares dominantes e residuais, que permitiam o desenvolvimento de novas vias funcionais a partir de áreas não lesadas do sistema nervoso central.

Bobath $(1950)^{4}$ constatou que a inibição espontânea dos reflexos mais primitivos desaparece nas lesōes do sistema nervoso central, razão pela qual propôs um método no qual o paciente assume posturas inibidoras destes reflexos; este autor admitia que a alteração da postura modifica o influxo aferente (sensitivo) o qual, por sua vez, altera o tono muscular e permite maior liberdade aos movimentos voluntários. Phelps (1941) ${ }^{21}$, tomando por base os reflexos condicionados de Pavlov, admitia que os métodos que utilizam o condicionamento têm suas indicaççes e seriam particularmente benéficos ao se considerarem os vários tipos de movimentos automaticamente adquiridos pelos recém-nascidos e pelas crianças em desenvolvimento. Assim, por exemplo, a movimentação passiva repetida e recíproca dos membros inferiores, quando acompanhada por estímulos auditivos (canto ritmado) que visam a condicionar o movimento recíproco, resultaria em recuperação gradativa dos padrões normais dos movimentos voluntários.

Outras formas de facilitação consistem na aplicação de estímulos periféricos nociceptivos (excitação direta de exteroceptores e indireta de proprioceptores), que ativam as vias reflexas segmentares e, consequentemente, forçam a passagem de influxos nervosos pelas sinapses funcionalmente inativadas pelas lesōes medulares ou periféricas.

Dentre essas técnicas, as de Rood (1954) ${ }^{23}$ e de Brüunstrom (1956) 7 têm sido usadas: a primeira consiste na ativação de reflexos segmentares mediante a aplicação de estímulos com um pincel sobre a área cutânea que recobre o músculo durante período de cinco minutos; a segunda promove a inibição de músculos espásticos mediante a percussão repetida, durante três minutos, dos músculos antagonistas. Durante o período de facilitação dos músculos o paciente tenta executar movimentos voluntários; repetições frequentes irão permitir que o paciente consiga enviar o tipo correto de influxo. Mais recente é o emprego do reflexo de vibração tônica (RTV). Embora o RVT tenha sido observado e estudado experimentalmente há cerca de dez anos, somente em 1969 Eklund e Steen ${ }^{11}$ passaram a utilizar e observar os efeitos da vibração muscular na espasticidade, rigidez e disfunção cerebelar. Verificaram estes autores que vibrações mecânicas de alta frequencia aplicadas a um músculo estriado tendem a induzir uma contração tônica reflexa neste músculo e relaxamento de seus antagonistas. Nestas técnicas. a par da inibição de grupos musculares geralmente espásticos, e da facilitação de grupos musculares não espásticos, são usados exercicios que visam a restabelecer o equilíbrio agonistaantagonista. Durante a execução de movimentos existe uma interdependência sensitivo-motora e, segundo Eldred e Hagbarth (1954) ${ }^{12}$, há até conexão funcional definida entre os músculos e as áreas cutâneas que os recohrem. 
Asratyan (1963) 2, em estudos realizados em dois grupos de cães (controle e experimental) com secção da medula espinal e desaferentação unilateral da pata posterior, pôde observar as alteraçōes estruturais e funcionais que ocorrem durante a hiper e/ou a inatividade. O grupo controle recebeu somente cuidados pós-operatórios e, consequentemente, o sistema reflexo da porção distal da medula espinal seccionada destes animais foi mantido em condições de relativo desuso; os cães do grupo experimental foram submetidos a massagens, movimentação fassiva e estimulação elétrica percutânea da pata e da ponta da cauda durante 30 minutos diariamente sendo, portanto, submetidos à ativação do aparelho reflexo correspondente aos segmentos de medula espinal distais à transecção. Este tipo especial de reeducação teve inicio em alguns animais decorridas 1 a 2 semanas do pós-operatório, enquanto que, em outros, foi aplicado 2 meses após a transecção. Acompanhando a evolução destes animais durante período variável de 3 a 12 meses Asratyan verificou que: $a$ ) os animais do grupo controle eram incapazes de se manter em pé e/ou realizar qualquer atividade locomotora, enquanto os cães do grupo experimental ficavam em pé à custa de seus próprios meios e, às vezes, trocavam alguns passos utilizando as patas posteriores; b) a atividade reflexa do grupo controle se caracterizava por aumento gradual até o $2^{\circ}$ mês, seguido por declínio, até que, no $6^{\circ} / 7^{\circ}$ mês, atingia sua estabilidade, enquanto no grupo experimental esta atividade dos segmentos distais era muito maior, desenvolvia-se rapidamente e mantinha sempre intensidade e amplitude elevadas estabilizando-se no $30^{\circ}$ dia de pós-operatório; c) o exame histológico revelou alterações morfológicas das células dos segmentos distais, sucerponiveis às alterações funciona:s.

Estes achados concordam com o que se observa em clínica, sendo de destacar a importância do treinamento e o tempo decorrido até seu início, na atividade reflexa da medula espinal seccionada do homem. Aparentemente a precocidade da aplicação de exercicios (estimulação precoce da atividade reflexa da medula espinal) impede que se instalem alterações distróficas dos neurônios que perderam suas conexōes com centros nervosos superiores.

Basmajian (1971) ${ }^{3}$, ao participar do grupo que reuniu as maiores autoridades em medicina física para discutir as bases neurofis.ológicas e a metodologia do emprego de exercícios terapêticos, isto é, as várias formas de facilitação neuromuscular em pacientes com lesões cerebrais, concluiu que, na prática, vários métodos se identificam com as técnicas que reforçam um ou outro dos princípios neurofisiológicos básicos conhecidos. Ao esclarecer e divulgar os denominadores comuns destas técnicas, destaca: a) a habilidade manual é de capital importância em todas as técnicas, sendo que o fisioterapêta deve ter a capacidade de captar as respostas do paciente para em seguida a elas reagir de modo conveniente; $b$ ) as técnicas manuais visam a obter respostas que acompanham o desenvolvimento normal do sistema nervoso ou então fundamentam-se em princípios neurofisiológicos de facilitação e inibiç̃̃o; $c$ ) a estabilidade postural e a motilidade controlada voluntariamente constituem os objetivos principais destas técnicas; $d$ ) a rotina de reaprendizado e condicionamento utilizando padrões e sequências, graus de ensinamento, repetiç̃̃o, reforço ค o máximo da capacidade mental do paciente. fazem parte de todas as técnicas. 
Bucy (1968) ${ }^{9}$ considera que os mecanismos hásicos responsáveis pelo controle da motricidade voluntária são ainda pouco compreendidos e extremamente complexos; no homem, bem como nos primatas inferiores, o trato piramidal não constitui a única conexão corticospinal envolvida no movimento; esse trato é essencial na realização de movimentos enérgicos, bem coordenados e úteis; a lesão isolada do piramidal não promove paralisia, espasticidade, hiperreflexia e abolição dos reflexos abdominais, mas é responsável pelo aparecimento do sinal de Babinski; no homem um mecanismo neural multisináptico envolvendo centros corticais, núcleos subcorticais e espinais funciona em conjunto com o piramidal e é capaz de atuar de modo efetivo sem ele; os mecanismos compensadores mobilizados após a inativação do sistema piramidal são, por ora, desconbecidos.

Granit (1972) ${ }^{13}$ e Brodal (1973) ${ }^{6}$ introduziram novos conceitos relativos à motricidade voluntária. Enquanto Granit ${ }^{15}$ demonstrou que existe uma sensação do estado de distensão muscular que, provavelmente mediante a ativação dos fusos musculares, faz com que ela se torne consciente, exercendo, assim, papel importante na apreciação dos movimentos, Brodal ${ }^{6}$ denomina de "força de inervação" a energia consicente necessária para que o músculo ou grupo de músculos paréticos se contraia. Esta última é subjetiva e é percebida como se fora um tipo de força mental ou força de vontade que, através da inervação voluntária, deve sobrepujar a resistência oposta e preexistente do músculo parético.

Segundo Brodal 6 , a força de inervação é, obviamente, um tipo de "energia mental" que não pode ser melhor definida ou quantificada e que se traduz pela contração do(s) músculo(s) em questão; a energia dispendida é muito grande, podendo atingir mesmo à exaustão, fator importante quando se trata de fisioterapia; embora se trate de complexo problema psicossomático, é provável que a energia mental seja, em última análise, transformada em energia mecânica. Brodal acredita que, na reeducação das paralisias, a movimentação passiva é necessária visando à profilaxia de retraçōes da cápsula, ligamentos e músculos, sendo ainda assunto controvertido o seu emprego visando à facilitação da contração subsequente e ativa dos músculos. Em sua experiência, esta facilitação indubitavelmente ocorre, particularmente nas fases iniciais do retorno da capacidade para o músculo responder a um impulso voluntário. Assim é que, na fase inicial, embora o paciente utilize toda sua vontade, é incapaz de mover uma dada articulação, como, por exemplo, a pronação do pé; se este movimento for executado passivamente e repetidas vezes pelo fisioterapêuta, o paciente poderá vir a executá-lo e, em dadas circunstâncias, com menor esforço. As informações sensitivas desencadeadas durante a movimentação passiva provavelmente auxiliam o paciente a dirigir a "força de invervação" através de vias apropridas. A melhora assim obtida não estaria relacionada com a diminuição ou abolição da resistência oposta ao movimento passivo (hipertonia) e à liberação da retração de estruturas articulares, pois o fenômeno foi observado nas articulações cuja amplitude era normal à movimentação passiva. Existem, provavelmente, delicados mecanismos neurofisiológicos que seriam os verdadeiros responsáveis pela facilitação dos movimentos, mecanismos estes 
semelhantes àqueles que ocorrem durante o aprendizado de toda e qualquer atividade motora Dentre a grande variedade de movimentos mais ou menos inadequados, o único correto é reconhecido como tal mediante as informações sensitivas que retornam ao SNC. $\mathrm{Na}$ fase seguinte do treinamento esta informação é utilizada na seleção do movimento correto. Ainda é controvertido se as sensações musculares (exclusive a dor) se tornam conscientes e até que ponto elas contribuem para o reconhecimento dos movimentos e das posições articulares. A este propósito é importante a implicação ou não de impulsos aferentes provindos dos fusos musculares.

Granit (1972) ${ }^{15}$, em investigaçōes experimentais realizadas em gatos e macacos, verificou que impulsos de aferentes primários (fibras aferentes Ia) dos fusos musculares evocam potenciais no córtex sensitivo-motor Embora ainda não se saiba até que ponto estes potenciais são conscientemente percebidos pelos animais, o fato de atingirem o córtex sugere que, em última análise, participam no controle motor. Goodwin, McCloskey e Eklund (1972) ${ }^{14}$ acreditam que, no homem, as informações sensitivas provindas dos músculos e receptores articulares contribuem em grande parte para a avaliação consciente da posição dos membros e os fusos musculares seriam, portanto, importantes receptores das sensações cinestésicas $\mathrm{Na}$ complementação destas idéias Brodal ${ }^{6}$ sugere que a hiperatividade dos fusos musculares facilita o reconhecimento subjetivo da distensão dos músculos

Em condições normais os delicados movimentos dos dedos da mão que têm sequência apropriada são executados automaticamente e, quando executados pela primeira vez, não podem dispensar o auxílio da atenção consciente. Por outro lado, nos pacientes paréticos os dedos não sabem mais qual a sequência dos movimentos e a sensação é semelhante àquela de alguém que está recitando um poema desconhecido ou cantando uma canção que havia esquecido. O retardo na sucessão dos movimentos, devido à paresia e espasticidade, interrompe uma cadeia maior de movimentos automáticos. Se a atenção for conscientemente dirigida para os movimentos dos dedos sua execução, ao invés de melhorar, piora e às vezes é impossível.

Exemplo típico do que se pode denominar de ato motor normal e automatizado, com interposição em série de movimentos particulares e coordenados dos dedos, é dado pelo ato de fazer o nó de uma gravata. Em se tratando de ato motor complicado e adquirido mediante o aprendizado ele se assemelha, sob vários aspectos, a outros atos nos quais o aprendizado se superpõe às capacidades inatas como, por exemplo, a marcha. Ao analisar o ato de trocar passos durante a marcha Lundberg (cit. por Brodal ${ }^{6}$ ) verificou que o mecanismo básico de ativação alternada de extensores e flexores é, provavelmente, programado na medula espinal, embora não faça parte da via reflexa, sendo mais provável que a programação básica da marcha seja, em parte, modificada pelo aprendizado.

A este propósito é importante lembrar um fato assinalado por Granit (1972) ${ }^{15}$ : "os movimentos considerados voluntários são, na realidade, em grande parte automáticos e, em sua maioria, só se tornam conscientes a partir do momento em que são solicitados para entrar em ação". Em pacientes paré- 
ticos a solicitação para executar o ato motor não está comprometida Aparentemente, o que falta é a capacidade de os movimentos prosseguirem automaticamente após o inicio do comportamento motor, razão pela qual os pacientes não conseguem realizá-los com a mesma agilidade (velocidade e destreza) que a de indivíduos normais. Os neurônios que constituem o substrato anatômico responsável pelos programas neurais e, consequentemente, pela inervação em sequência apropriada e que exercem sua ação sobre os motoneurônios alfa e gama não têm localização precisa

Granit 15 é favorável à hipótese de que parte do comportamento fundamental dos movimentos delicados é organizado em nível espinal, pois os movimentos resultantes da estimulação elétrica do córtex cerebral em nada se assemelham aos movimentos ágeis de individuos normais.

Embora Von Monakow (cit. por Lashley ${ }^{20}$ ), Van Buskirk ${ }^{25}$ e Boyle e Scalzitti ${ }^{5}$ considerem que a recuperação espontânea da função e, em particular, da motricidade, torna até certo ponto inútil o emprego de programas de exercícios (reaprendizado estafante e dispendioso), para Forgays ${ }^{13}$, Kabat, ${ }^{18}$, Rusk ${ }^{24}$, Grochmall ${ }^{16}$, Popova ${ }^{22}$ e outros, nas incapacidades devidas a lesões do sistema nervoso central, as funções que não se recuperam espontaneamente são passíveis de serem recuperadas mediante reeducação.

As dúvidas e as controvérsias persistem. Até que ponto a reeducação ou os programas de exercícios que visam ao reaprendizado interferem na recuperação espontânea da função? Todas as opiniões até agora emitidas permanecem no terreno das hipóteses, carentes de comprovação experimental.

Os pacientes com paralisia constituem um grupo na qual a sequela decorre, independentemente da causa, da lesão de um dos componentes do mecanismo neuromuscular $\mathrm{O}$ tratamento de qualquer tipo de paralisia visa a obter o máximo de recuperação motora e a reduzir ao mínimo a incapacidade funcional.

A recuperação da motricidade pode ocorrer espontaneamente em algumas situações: nos traumatismos, por exemplo, a recuperação espontânea ocorre $\mathrm{cm}$ virtude da absorção progressiva do edema, bem como do recobro da função em motoneurônios que não foram destruídos; nas hemiplegias devidas a hemorragia ou trombose cerebral a melhora espontânea ocorre depois que o edema regride. Acrescente-se, entretanto, que a recuperação da função parece decorrer também de processos compensadores mediante os quais as vias extrapiramidais substituem o trato corticospinal lesado.

É sabido que um neurônio destruído não mais se regenera. Por outro lado, no sistema nervoso periférico as fibras musculares inervadas pelos motoneurônios lesados atrofiam, degeneram e, eventualmente, desaparecem e são substituídos por tecido gorduroso ou fibroso. Nenhuma terapêutica que visa diretamente as fibras musculares desnervadas e/ou seus motoneurônios destruídos dará resultado. A recuperação ocorre em motoneurônios parcialmente lesados mas não destruídos e potencialmente capazes de funcionar novamente

Tais fatos nos levariam a admitir que os vários métodos de tratamento em nada contribuem para a recuperação motora. Além disso, alguns autores 
observaram resultados semelhantes em grupos de pacientes tratados e não tratados.

Para os adeptos da "teoria do uso e desuso", durante o período de recuperação esfontânea (que em muitos casos é bastante prolongado) o paciente nāo tratado perde o interesse em se utilizar de seus segmentos paralisados; estabelece-se, assim, um desgaste secundário da função motora, que se superpõe à patologia orgânica original; a recuperação motora torna-se difícil, podendo mesmo provocar, e posteriori, a perda progressiva da função. Esta não se traduz exclusivamente pela atrofia muscular e fadiga precoce dos músculos. mas também pela diminuição acentuada na função dos complexos mecanismos do sistema nervoso central, responsáveis pelo inicio, controle e coordenação dos movimentos voluntários.

As técnicas de reeducação muscular visam a ativar os centros motores. particularmente os neurônios latentes de casos cuja evolução se faz de forma subaguda ou crônica.

De particular importância é a existência, ou não, de motoneurônios em estado latente nos casos nos quais, durante o exame neuromuscular (testes manuais e quantificação clínica), não ocorre qualquer contração quando o paciente tenta executar um movimento voluntário (força muscular igual a zero). Entretanto, quando os centros motores são estudados mediante a utilização dos métodos de facilitação, tais músculos são passíveis de se contrair e até mesmo de realizar um ato voluntário. Isto indicaria que as células nervosas não foram totalmente destruídas mas sim que algumas estão potencialmente capazes de funcionar, não o fazendo em virtude de terem sido até então atingidas por estímulos de baixo limiar.

A continuidade do tratamento durante período de tempo variável restaura a função das células antes latentes e, ulteriormente, a contração voluntária poderá vir a se realizar sem o auxilio da facilitação.

A multiplicidade de conexões dos neurônios intercalares permite supor que os estímulos podem atingir os motoneurônios latentes mediante rotas indiretas e, assim, alcançar o limiar suficiente para a pós-descarga dos mesmos; por outro lado, a passagem de influxo voluntário é facilitada pela diminuição da resistência. sináptica.

Há 20 anos lidando com pacientes apresentando incapacidades motoras devidas a lesões do sistema nervoso acredito que a terapêutica por exercício ocupa lugar de destaque na recuperação da motricidade, sendo mesmo essencial para que o retorno da função motora se faça de forma mais completa mesmo na vigência de recuperação espontânea. Além dissso, o tratamento não só reduz o tempo necessário para a recuperação funcional, como também torna mais eficiente e útil a força muscular residual.

Embora o estado atual de nossos conhecimentos ainda não permita compreender em seu todo os complexos mecanismos do recobro da função, bem como afirmar que os programas de exercícios possuam base cientifica apesar de se utilizarem de fundamentos neurofisiológicos, eles constituem, na realidade, a única terapêutica que consegue acrescentar algo mais à recuperação espontânea do paciente. 


\section{RESUMO}

São atualizados os conceitos emitidos a propósito das várias técnicas (programas de exercícios) que visam a recuperar deficits motores devidos a lesão do sistema nervoso central, propiciando, assim, elementos que se constituirão em pontos de partida para debater e esclarecer os intrincados mecanismos envolvidos na reeducação e recuperação da função motora.

\section{SUMMARY}

\section{Reeducation and recovery of motor function in lesions of the central nervous system.}

A review is made of the current concepts on the several techniques (kinesitherapy programs) used with the purpose of recovering motor impairments caused by damage of the central nervous system. In this way data are gathered for the discussion and explanation of the intricate mechanisms involved in reeducation and recovery of the motor hability.

\section{REFERENCES}

1. ANGHINAH, A. - Recuperacão espontânea da função nas lesões do sistema nervoso central. Arq. Neuro-Psiquiat. (São Paulo) 33:363, 1975.

2. ASRATYAN, E. A. - The effect of use and disuse on the morphology and function of spinal neurones. In Gutmann \& Pavel's - The effect of use and disuse on neuromuscular functions. New York, Elsevier, 1963. p. 213.

3. BASMAJIAN, J. V. - Neuromuscular facilitation tecniques. Archs. phys. Med. Rehabil. 52:40-42, 1971.

4. ВОВАTH, E. \& BOBATH, B. - Spastic paralisis: treatment by use of reflex inhibition. Brit. J. Phys. med. 13:121-127, 1950.

5. BOYLE, R. W. \& SCALZITTI, P. D. - A study of 480 consecutive cases of cerebral vascular accident. Archs. phys. Med. Rehabil. 44:19-28, 1963.

6. BRODAL, A. - Self observations and neuro-anatomical considerations after a stroke. Brain, 96:675-694, 1973.

7. BRUUNSTROM, S. - Associated reactions of upper extremities in adult patients with hemiplegia: an approach to training Phys, Ter. Rev. 36:22-30, 1956.

8. BUCY, P. C. - Is there a pyramidal tract? Brain 80:376-392, 1957.

9. BUCY, P. C. - Neuromechanism controlling skeletal muscular activity and its unsolved problems. Neurosc. Research 1:251-260, 1968.

10. DENNY-BROWN, D. - Desintegration of motor function resulting from cerebral lesion. J. nerv. ment. Dis. 112:1-45, 1950.

11. EKLUND, G. \& STEEN, M. - Muscle vibration therapy in children with cerebral palsy. Scand. J. Rehab. Med. 1:35-37, 1969.

12. ELDRED, E. \& HAGBARTH, K.E. - Facilitation and inhibition of gamma afferents by stimulation of certain skin areas. J. Neurophysiol, 17:59-65, 1954.

13. FORGAYS, D. G. - A note on reeducation and restitution of function. $J$. nerv. ment. Dis. 118:363-368, 1953.

14. GOODWIN, G. M.; McClOSKEY, D. T. \& MATTHEWS, P. B. C. - The contribution of muscle afferents to kinaesthesia. Brain 95:705-748, 1972.

15. GRANIT, R. - Constant errors in the execution and appreciation of movement. Brain 95:649-660, 1972. 
16i. GRocilmal, S. -. Therapeutical gymnastics in the spastic hemiplegla. Neurol. Neurochir. Psychiat. pol. 5:39-56, 1955. Resumo em Inglês.

17. JACKSON, J. H. - Selected Writings of J. H. Jackson, 2 vol. editados por J. Taylor cóm assisténcla de G. Holmes e F. M. R. Walshe. London, Hoclder e Stoughton, 1931.

18. KABAT, H. - Restoration of function through neuromuscular reeducation in traumatic paraplegia. Arch. Neurol. Psychiat. 67:737-744, 1952.

19. KRUSEN, F. - History and development of physical medicine. In Watkins "Physical medicine in general practice" New York, Lippincott, 1946, p. 1.

20. I.ASHLEY, K. S. - Factors limiting recovery after central nervous lesions. J. nerv. ment. Dis. 88:733-755, 1938.

21. PHELPS, W. - The rehabilitation of cerebral palsy Sth. med. J. Bgham Ala. $34: 770-776,1941$.

22. POPOVA, N. A. - Methods and mechanism for the recovery of motor function alter central paralysis of cerebral origin (texto em russo) Klin. ed. (Mosk.) 33: 38-45, 1955. Resumo in Excerpta med. (Amst.), Sect. VIII, 10:862-863, 1957.

23. HROD, M. - Neurophyslological reaction as a basis for physical therapy. Phys. Ther. Rev. 34:40-46, 1954.

24. RUSK, H. - Hemiplegia and Rehabilitation. Ed. Institute of Physlcal Medicine and Rehabllitation, New York University, Bellevue Medical Center, 1958.

25. VAN BUSKIRK, E. - Return of motor function in hemiplegia. Neurology 4: 919-928, 1954.

Clínica Neurológica - Faculdade de Medicina, Universidade de Sāo Paulo Caixa Postal 3461 - 01000 Sĩo Paulo, SP - Brasil. 